\title{
Justicia en Conflicto y Conflictos sobre Justicia: el Derecho Internacional Penal en Tiempos de Altas Expectativas
}

\section{Justice in Conflict and Conflicts about Justice: International Criminal Law in Times of High}

\author{
Fannie Lafontaine ${ }^{1}$ \\ Universidad Laval (Canadá)
}

Recibido: 30-05-14

Aprobado: 15-06-14

\section{Resumen}

En este ensayo se analizan algunos aspectos del contexto que marca el nacimiento de la jurisdicción penal internacional permanente - la Corte Penal Internacional (CPI)- a saber, las expectativas que se colocaron en las instituciones de justicia penal internacional en los años 90 y posteriores, y el fracaso parcial de estas instituciones para mantenerse a la altura de esas previsiones poco realistas. Posteriormente se abordan algunos elementos de consideración para el futuro del sistema de justicia penal internacional. Se tratan algunos de los fundamentos sobre los que el sistema está construido, sirviendo de base para el argumento de que a pesar de un legado mixto y diversas deficiencias, no habrá marcha atrás hacia un vacío legal en el Derecho internacional en lo relativo a la rendición de cuentas por crímenes internacionales.

Palabras-clave: paz y justicia, rendición de cuentas, crímenes internacionales, CPI, jurisdicción universal, impunidad.

\footnotetext{
${ }^{1}$ (fannie.lafontaine@fd.ulaval.ca) Abogada, Profesora agregada, Titular de la Cátedra de Investigación de Canadá sobre Justicia Penal Internacional y Derechos Humanos, Fundadora y Co-directora de la Clínica de Derecho Penal Internacional y Humanitario, Facultad de Derecho, Universidad Laval, Quebec, Canadá. La autora desea agradecer a Javier Torres por la ayuda inestimable en la preparación de este ensayo. Entre sus publicaciones, cabe citar Prosecuting Genocide, Crimes against Humanity and War Crimes in Canadian Courts, Carswell, 2012; "Universal Jurisdiction: The Realistic Utopia", 10 Journal of International Criminal Justice, 2012.
} 


\begin{abstract}
This paper analyzes some aspects of the context that marks the birth of the permanent international criminal court - the International Criminal Court (ICC)namely the expectations that were placed upon the institutions of international criminal justice in the 90s and later, and the partial failure of these institutions to live up to these unrealistic expectations. Subsequently some elements of consideration for the future of the international criminal justice system are addressed. It discusses some of the foundations on which the system is built, providing the basis for the argument that despite a mixed legacy and various deficiencies, there will be no turning back to a legal void in international law with regard to accountability for international crimes.
\end{abstract}

Key-words: peace and justice, accountability, international crimes, ICC, universal jurisdiction, impunity.

\title{
Introducción
}

El tema más debatido en las últimas décadas sobre el lugar que ocupan los tribunales penales internacionales en los asuntos internacionales ha sido probablemente la polémica tensión entre priorizar la paz e insistir al mismo tiempo en la justicia para los crímenes más graves de la guerra. Con una Corte Penal Internacional (CPI) operando actualmente en medio de conflictos armados en curso, y siendo capaz de emitir órdenes de arresto en contra de las partes en conflicto y de los funcionarios ubicados en el nivel más alto del liderazgo político y militar, la justicia puede ser vista como una herramienta para prevenir más atrocidades o como un impedimento para la paz. La justicia puede ser el único lugar en que las víctimas pueden ser escuchadas, pero puede también ser secuestrada por los poderosos para sus propios intereses de protección. En esta disyuntiva, aparentemente infranqueable, ¿pueden los tribunales "comunicar ley al poder"2 o ha perdido la ley todo su poder?

Algunos de los desafíos más complejos del sistema de justicia global puesto en marcha para hacer frente a genocidios, crímenes de lesa humanidad y crímenes de guerra incluyen los problemas de selectividad y politización. Ante el rostro de un Tribunal Penal Internacional para Ruanda (TPIR), que falló en no mirar a ambos lados del conflicto, o de una CPI cuyas investigaciones se encuentran hasta el momento centradas exclusivamente en asuntos de África, observadores y participantes de estas jurisdicciones internacionales han comenzado a cuestionar si la justicia dada a los crímenes internacionales es de

2 P. W. Kahn, Speaking Law to Power: Popular Sovereignty, Human Rights, and the New International Order, 1, "Chicago Journal of International Law", 2000, pp. 1-18. 
hecho verdadera justicia, de acuerdo con el estado de derecho, o más bien (in) justicia para unos cuantos desafortunados que cayeron en la desaprobación de las superpotencias. El recorte a la jurisdicción universal en países como España pudiera parecer como la rendición del estado de derecho a la conveniencia económica y política.

Estas y otras son inquietudes legítimas que deben ser discutidas y confrontadas si la idea de justicia para los peores crímenes conocidos por la humanidad ha de sobrevivir a su propio renacimiento a mediados de los años 90, después de la larga parálisis de la Guerra Fría que siguió a la Segunda Guerra Mundial y a los tribunales militares erigidos para juzgar a los nazis y miembros del Eje. En cierto sentido, la evolución palpable de cualquier sistema de justicia, incluido el sistema de justicia penal internacional, se basa en la capacidad de indignación de sus observadores. Es esta indignación y aquellos ataques asertivos a la ley lo que impide que el sistema de justicia internacional se convierta en un jovial circo de bienhechores dándose palmadas de satisfacción entre sí cada vez que un 'criminal de guerra' más va a la cárcel. Dicho esto, debemos también ser precavidos al adoptar posiciones extremas o sin matices sobre el sistema: debemos andar precavidos frente a aquellos idealistas que ven la justicia penal internacional como una panacea y como el logro más grande de la humanidad, al igual que debemos andar precavidos frente a aquellos cínicos sin esperanza que la ven como una empresa completamente inútil y corrupta.

En este breve ensayo deseo discutir algunos aspectos acerca del contexto que marca el nacimiento de la jurisdicción penal internacional permanente la Corte Penal Internacional (CPI)-, a saber, las expectativas depositadas en las instituciones de justicia penal internacional en los años 90 y posteriores, y el fracaso parcial de estas instituciones a la hora de mantenerse a la altura de esas previsiones poco realistas (1). Posteriormente me referiré a algunos elementos de consideración para el futuro del sistema de justicia penal internacional. Mencionaré algunos de los fundamentos sobre los que está construido, sirviendo de base para el argumento de que a pesar de un legado mixto y diversas deficiencias, no habrá marcha atrás hacia un vacío legal en el derecho internacional en lo relativo a la rendición de cuentas por crímenes internacionales. También hablaré del gradual y prometedor traspaso de responsabilidad de los organismos internacionales hacia los Estados en la investigación y el enjuiciamiento de crímenes internacionales (2).

\section{El Contexto: (No) Colmar Expectativas Irreales a. Altas Expectativas para la Justicia Internacional Penal}

La creación de los tribunales ad hoc en la década de los 90 y la adopción 
del Estatuto de Roma de la Corte Penal Internacional en 1998 impulsó una ola de emoción y enorme esperanza en la comunidad de derechos humanos y en las víctimas de atrocidades. Las violaciones graves al derecho internacional de los derechos humanos y al derecho internacional humanitario serían oponibles en contra de los individuos responsables de cometerlas. Aun cuando la comunidad internacional fuera o no capaz de prevenir crímenes, al menos podría asegurarse de que éstos no quedaran impunes. No obstante, aparte del castigo de quienes detentan la mayor responsabilidad por la comisión de crímenes masivos, se esperaba que las instituciones de justicia penal internacional desempeñasen un gran papel en la restauración y el mantenimiento de la paz y la seguridad.

En 1993, el Consejo de Seguridad de la ONU declaró que "el establecimiento [...] de un tribunal internacional y el enjuiciamiento de los presuntos responsables de graves violaciones al derecho internacional humanitario podría [...] contribuir a la restauración y mantenimiento de la paz" ${ }^{3}$. Era la primera vez que la creencia de que la responsabilidad penal podría ser esencial para la restauración y el mantenimiento de la paz y la seguridad se expresaba de manera explícita. Las violaciones masivas a los derechos humanos, incluidas las cometidas dentro de las fronteras de un Estado, fueron consideradas como amenazas a la paz y seguridad internacional, y la rendición individual de cuentas por tales violaciones, como una medida para restaurarlas o mantenerlas. Este objetivo se convirtió en una tendencia, ya que todos los tribunales internacionales e internacionalizados creados desde entonces lo persiguieron en niveles más o menos explícitos ${ }^{4}$.

Pero este no fue el único objetivo que se esperaba alcanzasen los tribunales penales internacionales. En efecto, la justicia penal internacional fue vista como una forma de disuadir no sólo al autor individual, sino de actuar también como un elemento de disuasión general para la comisión de crímenes internacionales en todo el mundo y para prevenir la proliferación de la guerra o, en última instancia, disminuir la capacidad de un grupo de cometer transgresiones. Por

${ }^{3}$ Consejo de Seguridad de las Naciones Unidas, Res. 827, 60 párrafo del preámbulo. "The establishment [...] of an international tribunal and the prosecution of persons responsible for serious violations of international humanitarian law would [...] contribute to the restoration and maintenance of peace".

${ }^{4}$ Consejo de Seguridad, 'Tribunal (ex Yugoslavia)’ (TPIY), UN Doc. S/RES/827 (1993), $6^{\circ}$ párr. del preámbulo; Consejo de Seguridad, 'establecimiento de un Tribunal Internacional y la adopción del Estatuto del Tribunal' (ICTR), UN Doc. S/RES/955 (1994), $7^{\circ}$ párrafo del preámbulo. En cuanto al Tribunal Especial para Sierra Leona (TESL), véase Consejo de Seguridad, 'Situación en Sierra Leona', UN Doc. S/RES/1315 (2000), $7^{\circ}$ párr. del preámbulo; para la Corte Penal Internacional (CPI), véase 1998 Estatuto de Roma de la Corte Penal Internacional, 2187 UNTS 3, $3^{\circ}$ y $5^{\circ}$ párrs. del preámbulo, y Art. 13 (b). Vínculos similares entre la paz y la justicia se pueden encontrar en lo que respecta al establecimiento de los Grupos Especiales en Timor-Este: Consejo de Seguridad, 'Situación en Timor-Este' UN Doc. S/RES/1272 (1999), 25 de octubre de 1999, preámbulo y párr. 1; Los juicios de los Jemeres Rojos en Camboya: Asamblea General, ‘Juicios de los Jemeres Rojos', UN Doc. A/RES/57/228 B, 22 Mayo de 2003, preámbulo y Tribunal Especial para el Líbano: Consejo de Seguridad, 'Situación en Medio Oriente' UN Doc. S/RES/1757 (2007), 30 de mayo 2007, preámbulo. 
otra parte, también se esperaba que los tribunales penales internacionales dijeran la verdad y arrojasen luz sobre acontecimientos, proporcionando una sensación de justicia para las víctimas. Tenían, además, un papel "educativo" dirigido a "transmitir el mensaje de que las normas del derecho internacional humanitario deben ser obedecidas bajo cualquier circunstancia"s. También se pensaba que permitirían, a víctimas y perpetradores, reconciliar y reintegrar sociedades desgarradas en un país donde se hubiera restablecido el Estado de derecho ${ }^{6}$.

Incluso con una visión general así de rápida y no exhaustiva, cabe fácilmente observar que se pusieron expectativas muy altas en la justicia penal internacional, estableciendo en consecuencia un umbral muy elevado para su éxito. Hoy en día, en el contexto del trabajo de las instituciones penales internacionales, yace una tarea muy difícil, la de gestionar expectativas: las expectativas de los Estados, de la sociedad civil, de la "opinión pública" y, sobre todo, las de las víctimas. Como expone dramáticamente Rob Crilly:

(...) la multitud de niños, sus ojos llenos de esperanza al sostener sus carteles escritos a mano pidiendo a la ONU y a la CPI salvar al pueblo de Darfur [...] fue una de las escenas más deprimentes que yo haya visto siquiera. En cierto modo, es más fácil lidiar con la miseria, con las madres sosteniendo niños esqueléticos mientras narran cómo fue quemado su pueblo y sus hombres asesinados (...) Lo que es infinitamente más difícil de tratar es la esperanza: la creencia de que el mundo exterior puede resolver los problemas de Darfur; que los soldados de la ONU algún día vendrán al rescate; o que la CPI va a terminar con la cultura de impunidad en Sudán?

\section{b. Un legado mixto previsible}

En vista de tan elevadas expectativas, era de esperarse que las instituciones penales internacionales fueran vulnerables a las críticas. Por una parte, la interacción y la compatibilidad de la paz y la seguridad, de un lado, y la justicia del otro, se encuentran en el centro de un acalorado debate que

${ }^{5}$ El Fiscal contra Kordić y Čerkez, Sentencia, Caso No. IT-95-14/2-A, TPIY Cam. Ap., 17 de diciembre de 2004, párr. 1080 ('conveying the message that rules of international humanitarian law have to be obeyed under all circumstances').

${ }^{6}$ El Estado de derecho y la justicia de transición en las sociedades que sufren o han sufrido conflictos, Informe del Secretario General, S/2004/616, 23 de agosto de 2004, párr. 38.

7 Rob Crilly, Saving Darfur: Everyone's Favourite African War, Reportage Press, 2010, pág. 39-40 (énfasis añadido) ("...the crowd of children, their eyes wide with hope as they held their handwritten signs calling for the UN and ICC to save the people of Darfur... [...] was one of the most depressing sights I had even seen. In some ways it is easier to deal with misery, with mothers holding skeletal children as they tell how their village was burned and their menfolk killed. ... What is infinitely more difficult to deal with is hope: the belief that the outside world can solve the problems of Darfur; that the soldiers of the UN will one day ride to the rescue; or that the ICC will end Sudan's culture of impunity"). 
juega un papel en la mayoría, por no decir la totalidad, de los escenarios postconflicto, así como en situaciones actuales de violencia y abusos contra los derechos humanos. Como se mencionó en la introducción, la idea de que los mecanismos de justicia penal internacional pueden (contribuir a) restablecer la paz y la seguridad es uno de los temas de debate más candentes en la literatura y en los foros internacionales. Ciertamente, no hay una respuesta definitiva a este debate. Es evidente que la adopción de ciertas medidas de derecho penal para hacer frente a los crímenes internacionales no puede ser ignorada en los procesos de consolidación de la paz (aunque pudiera objetarse su retraso). Hay razones para recordar que el derecho internacional convencional ordena procesos penales para ciertos crímenes internacionales ${ }^{8} \mathrm{y}$, a su vez, por derecho internacional consuetudinario para otros ${ }^{9}$. Sin idealizar el potencial transformador de este tipo de juicios, soy de la opinión de que la justicia penal por crímenes internacionales tiene un papel que desempeñar en la recuperación post-conflicto y, también, en situaciones de conflicto en curso.

Dicho lo anterior, centrarse en la justicia penal internacional pudo haber ensombrecido el hecho, al menos en un principio, de que los juicios penales sólo pueden ser un elemento dentro de una compleja red de medidas que deben ponerse en práctica para lograr la transición de la guerra a la paz. Sólo las estrategias integrales concebidas sobre una base caso por caso, previa consulta con los grupos nacionales, incluyendo a los grupos más afectados por el conflicto, pueden aspirar a equilibrar "una variedad de objetivos, incluyendo la búsqueda de la responsabilidad, la verdad y la reparación, el mantenimiento de la paz y la construcción de la democracia y el Estado de derecho" ${ }^{10}$. Insistir en

${ }^{8} 1948$ Convención para la Prevención y la Sanción del Delito de Genocidio, 78 UNTS 277, artículo IV- VI; 1949 Convenio (I) para el mejoramiento de la suerte de los heridos y enfermos de las fuerzas armadas en campaña, 75 UNTS 31 (1950), art. 49; 1949 Convenio (II) para el mejoramiento de la suerte de los heridos, enfermos y náufragos de las fuerzas armadas en el mar, 75 UNTS 85 (1950), art. 50; 1949 Convenio (III) relativo al trato debido a los prisioneros de guerra, 75 UNTS 135 (1950), artículo 129 ; 1949 Convenio (IV) relativo a la protección debida a las personas civiles en tiempo de guerra, 75 UNTS 287 (1950), art. 146; 1977 Protocolo adicional a los Convenios de Ginebra del 12 de agosto de 1949 relativo a la Protección de las Víctimas de los Conflictos Armados Internacionales (Protocolo I), 1125 UNTS 3 (1979), arts. 85-87; 1973 Convención Internacional sobre la Represión y el Castigo del Crimen de Apartheid, 1015 UNTS 243 (1976), art. IV. Nótese que, como excepción, en el art. V, el ejercicio de la jurisdicción está redactado en términos permisivos («podrá»); 2006 Convención Internacional de Nueva York para la Protección de Todas las Personas contra las Desapariciones Forzadas (aún no entra en vigor), Doc.A/61/48, arts. 4-11; 1984 Convención de Nueva York contra la Tortura y Otros Tratos Crueles, Inhumanos o Degradantes, 1465 UNTS 85 (1987), arts. 4-7. La Jurisprudencia que interpreta diversos tratados regionales e internacionales de derechos humanos también ha reconocido cada vez más la obligación de enjuiciar a los responsables de violaciones a los derechos humanos: véase, por ejemplo, la revisión de A. Seibert-Fohr, Reconstruction through Accountability, 9, "Max Planck Year book of United Nations Law" (2005) 555.

${ }_{9}^{9}$ Véase la reseña de la discusión en, por ejemplo, Cryer et al., An Introduction to International Criminal Law and Procedure, Oxford, 2007, pp. 31-33 y 58-61.

${ }^{10}$ El Estado de derecho y la justicia de transición en las sociedades que salen de conflictos, Informe del Secretario General, supra nota 6, párr. 25. En las consultas nacionales, véase Oficina del Alto Comisionado para los Derechos Humanos (ACNUDH), Rule-of-law Tools for Post-conflict States: 
procesos penales sin prestar la debida atención a mecanismos complementarios y alternativos (legales y no legales) puede de hecho poner en peligro la búsqueda de la verdad, la justicia y la reconciliación. La complementariedad es necesaria no sólo con otros mecanismos - no penales- de justicia transicional, sino también, por ejemplo, con medidas judiciales y políticas destinadas a reconocer la responsabilidad del Estado por los crímenes cometidos ${ }^{11}$. Los diferentes enfoques de justicia transicional, a su vez, deben ser aplicados en coordinación con iniciativas paralelas tales como reformas al sector de la seguridad y al Estado de derecho, así como programas de desarrollo basados en derechos humanos ${ }^{12}$.

Ahora bien, incluso si se reconoce que la justicia penal tiene un papel que jugar en el mantenimiento o restauración de la paz y la seguridad, es necesario reconocer que los tribunales penales internacionales en ocasiones han tomado caminos que no son fáciles de conciliar con la idea de paz. Como ejemplo desconcertante, el fracaso del TPIR de no mirar a ambos lados del conflicto condujo muy probablemente a tensiones en Ruanda ${ }^{13}$. Los juicios penales pueden contribuir a la paz y a la reconciliación entre otras formas mediante la presentación de una "memoria colectiva precisa... basada en el modelo de clausura. Se dice que los crímenes de guerra permiten a sociedades enteras 'dibujar... una clara línea entre el pasado y el futuro, lo que permite el inicio de un proceso de sanación""14. Más allá de la clausura, que, se dice, es demasiado ambiciosa como agenda para los juicios penales, lo cierto es que se pueden promover debates sobre la historia de un conflicto o de casos específicos a través de la lente del derecho, lo que reduce las posibilidades de acusaciones

NationalConsultationsonTransitionalJustice (HR/PUB/09/2), 2009 ('a variety of goals, including the pursuit of accountability, truth and reparation, the preservation of peace and the building of democracy and the rule of law').

${ }^{11}$ Véase, S. Mohamed, A Neglected Option: The Contributions of State Responsibility for Genocide to Transitional Justice, 80"University of Colorado Law Review", 2009, p. 327.

${ }_{12}$ J. E. Stromseth, Pursuing Accountability for Atrocities After Conflict: What Impact on Building the Rule of Law?, 38 “Geo. J. Int'l L.”, 2006-2007, pp. 251-256; Oficina del Alto Comisionado para los Derechos Humanos, 'Frequently asked questions on a human rights-based approach to development cooperation', UN Doc. HR/PUB/06/8 (2006). Ver también la interesante propuesta de una justicia post-conflicto de emergencia que trabajaría junto a otras iniciativas de justicia, tales como los procesos penales internacionales: L. Otis and E. H. Reiter, Front-Line Justice, 46 "Virginia Journal of International Law" (2006) 677.

${ }^{13}$ Human RightsWatch, 'Rwanda: End Attacks on Opposition Parties', PressRelease, 10 de febrero de 2010 ('... [An opposition figure] has been widely condemned in official and quasi-official media and described as a "negationist" of the genocide for stating publicly that crimes committed against Hutu citizens by the RPF and the Rwandan army should be investigated and those responsible brought to justice').

${ }_{14}$ J. Alvarez, Rush to Closure: Lessons from the Tadić Judgment, 96 "Mich. L. Rev." (1998), pp. 2031-2034, citando a N. Roth-Arriaza, 'Introduction', in N. Roth-Arriaza (ed.), Impunity and Human Rights in International Law and Practice, New York, Oxford University Press, 1995, 3, pp. 7-8 ("an accurate collective memory ... based on the model of closure. It is said that war crimes trials permit entire societies to "draw [ ] a clear line between past and future, allowing the beginning of a healing process"').

Araucaria. Revista Iberoamericana de Filosofia, Política y Humanidades, año 16, n 32 . Segundo semestre de 2014. Pp. 339-358. ISSN 1575-6823 e-ISSN 2340-2199 doi: 10.12795/araucaria.2014.i32.17 
infundadas de ambas partes ${ }^{15}$. Sin embargo, los juicios penales post-conflicto pueden aspirar a cumplir esta promesa únicamente si miran a ambos lados de un conflicto. El TPIR, por razones de conveniencia política, fracasó abiertamente en este sentido.

Otro ejemplo, la decisión del entonces Fiscal de la CPI de acusar al presidente en funciones de Sudán, Omar Al- Bashir, por crímenes de lesa humanidad y genocidio en Darfur, fue un movimiento sorprendente en su momento por razones legales y estratégicas, y resultó ser devastador para la legitimidad y la credibilidad de la CPI. Jurídicamente hablando, fue muy aventurado dirigirse directamente a la cabeza de la jerarquía política sin haber cuestionado previamente la cadena de poder y de mando a través de otros casos de más bajo perfil, en una situación de gran complejidad como la de Darfur. Fue también bastante osado acusar al Presidente por el delito de genocidio, un delito muy difícil de probar, en un caso en el que incluso la Comisión Internacional de Investigación que analizó el problema, y cuyo informe motivó la remisión de la situación en Darfur a la CPI por el Consejo de Seguridad, no había encontrado pruebas suficientes para concluir que un genocidio había ocurrido ${ }^{16}$. Estratégicamente hablando, perseguir a un Presidente en funciones cuando el Estado difícilmente cooperaba con la Corte fue una garantía de rechazo y un presagio de que ningún presunto criminal de guerra de Darfur llegaría a La Haya. Esta decisión ha alejado a la Unión Africana y ha desencadenado una serie de posturas muy agresivas contra la CPI, llevando a la Corte al borde de la quiebra de sus relaciones con los Estados de África. Lo que el caso Bashir demuestra a su vez es que se debe tener cuidado con el exceso de confianza en la justicia penal internacional como instrumento de paz, al carecer de un fuerte patrocinio político, como el respaldo de un órgano como el Consejo de Seguridad. Aun cuando el Consejo ha encontrado que los procesos penales son una medida deseable para la restauración de la paz y la seguridad en una situación determinada, su falta de apoyo eficaz a la ejecución de medidas subsecuentes adoptadas dentro del sistema de justicia criminal socava seriamente la credibilidad del orden de justicia internacional: "la impunidad a través de la no ejecución de las órdenes internacionales de arresto que han sido avaladas con la autoridad del Capítulo VII no puede permitirse sin socavar en lo fundamental la credibilidad de la noción de un Estado de derecho internacional" ${ }^{17}$. Esta falta de seguimiento consecuente de la situación

\footnotetext{
${ }^{15}$ Alvarez, ibid., pp. 2084-2085.

${ }^{16}$ Informe de la Comisión Internacional de Investigación sobre Darfur al Secretario General - De conformidad con la Resolución del Consejo de Seguridad. 1564 (2004), de 18 de septiembre de 2004, doc. S/2005/60, 1 de febrero de 2005.

${ }^{17}$ C. Reiger, 'Fulfilling the Justice Promise: Guiding Principles for Resolving the Ongoing Responsibilities of International Tribunals', 8 de octubre de 2009, p. 2, http://www.ictj.org/static/ Prosecutions/Arria_Presentation091008.pdf: 'Impunity through non-enforcement of international arrest warrants that have been backed with Chapter VII authority cannot be permitted without 
de Darfur socava gravemente la credibilidad tanto de la CPI como del Consejo de Seguridad y debilita el orden jurídico internacional.

En cuanto a otras expectativas incumplidas, las esperanzas iniciales de las víctimas de tener una voz en los procesos penales internacionales no tardaron en ser decepcionadas ante los tribunales ad hoc. Las reparaciones para las víctimas no recibieron un estatus destacado en los tribunales penales internacionales ad hoc, los cuales se basaron en gran medida en el modelo del common law. Los estatutos del TPIY y del TPIR prevén la restitución de bienes adquiridos mediante conducta criminal cuando se haya hecho una declaración de culpabilidad, pero las víctimas no cuentan con un recurso directo para reclamar su restitución ${ }^{18}$. La víctima individual puede también reclamar una indemnización ante los tribunales nacionales u otros órganos competentes, una vez que el acusado ha sido condenado y el juicio se ha transmitido a las autoridades nacionales ${ }^{19}$. Estas disposiciones han tenido poco o ningún impacto en las víctimas relacionadas con los procedimientos ante los tribunales ${ }^{20}$.

Por otra parte, la idea de que los mecanismos de justicia penal internacional podrían desarrollar un relato preciso y detallado de la historia es bastante controvertida $^{21}$. Los procesos penales tienen como objetivo principal el de la determinación de la responsabilidad individual. En particular, donde se basen en un modelo acusatorio, no pueden esperar construir de manera realista un expediente completo de hechos de todo un conflicto o de años de abuso. Los tribunales ad hoc han sido criticados por intentar hacer eso $^{22}$.

Finalmente, si bien de manera general se entiende que "las soluciones duraderas y sustentables a la impunidad deben apuntar principalmente al fortalecimiento de la capacidad nacional para juzgar crímenes [internacionales]"23,

fundamentally undermining the credibility of the notion of an international rule of law'.

${ }^{18}$ Art. 24 (3) del Estatuto del TPIY y 23 (3) del Estatuto del TPIR; Reglas 98ter (B) y 105 de las Normas del TPIY de Procedimiento y Prueba (RPE); Reglas 88 (b) y 105 RPE TPIR.

${ }^{19}$ Regla 106 TPIY y TPIR RPE.

${ }^{20}$ Véase, por ejemplo, A-M De Brouwer, Supranational criminal prosecution of sexual violence: the ICC and the practice of the ICTY and the ICTR, Intersentia, 2005, pp. 394 s; W. A. Schabas, The UN international criminal tribunals: the former Yugoslavia, Rwanda and Sierra Leone, Cambridge, Cambridge University Press, 2007, pp. 149 s; S. Malstrom, Restitution of Property and Compensation to Victims, en Mayo y al. (eds), Essays on ICTY Procedure and Evidence in Honour of Gabrielle Kirk McDonald, Kluwer Law International, 2001, p. 376; M. Husejnovic and E. Mackic, Victims Miss Out on Right to Compensation, Balkan Investigative Reporting Network; Informe de Justicia, 4 de marzo de 2009 sobre indemnización a TPIY y ante la Sala de Crímenes de Guerra de Bosnia (ver. Art 112 del Código Penal de Bosnia-Herzegovina). En Ruanda, las órdenes de indemnización no se han aplicado: International Crisis Group, International Criminal Tribunal for Rwanda: Justice Delayed, 7 de junio de 2001, Informe de África No. 30.

${ }_{21}^{2}$ J. Alvarez, supra nota 14; M. Osiel, Mass Atrocity, Collective Memory and the Law, New Brunswick, New Jersey, Transaction Publishers, 1997; M. Minow, Between Vengeance and Forgiveness, Beacon Press, 1999.

${ }_{22}$ Véase, por ejemplo, El Fiscal contra Tadic, Caso No. IT-94-1-T, TPIY T. Ch., 7 de mayo de 1997; El Fiscal contra Akayesu, Sentencia, Caso No. ICTR-96-4-T, 2 de septiembre de 1998; para su crítica, véase, por ejemplo, J. Alvarez, Lessons from the Akayesu Judgment, 1998-1999, 5, "ILSA Journal of International and Comparative Law" 359; J. Alvarez, supra, nota 14.

${ }^{23}$ ACNUDH, Rule-of-law tools for post-conflict States: Prosecution initiatives, UN Doc. HR/ 
los mecanismos internacionales de justicia penal produjeron resultados mixtos. Los tribunales (híbridos) internacionalizados a menudo tienen un impacto profundo en la legislación nacional; sin embargo, los tribunales ad hoc tuvieron un perfil bajo y una ineficiente estrategia de fortalecimiento de capacidades, por lo menos en las etapas iniciales, y tomó tiempo antes de que estimulasen reformas legales a nivel interno. De hecho, el TPIY y el TPIR nunca vieron realmente el fortalecimiento de la capacidad nacional como parte central de su mandato hasta que su estrategia de conclusión tuvo que ser diseñada ${ }^{24}$. Su impacto se podría resumir como "demasiado poco, demasiado tarde" 25.

La CPI ha aprendido de estos fracasos controvertidos y ha elaborado un mecanismo innovador para la participación y la reparación de las víctimas. Se les ha otorgado a las víctimas un papel cada vez más destacado en los procesos penales internacionales. La CPI cuenta con diversas disposiciones relativas a la participación de las víctimas. Su estrategia se basa en los principios contenidos en los instrumentos internacionales relativos a los derechos de las víctimas ${ }^{26}$. Se basa en el hecho de que "... un compromiso positivo con las víctimas puede tener un efecto significativo en cómo las víctimas experimentan y perciben la justicia y, de ese modo, contribuir a su proceso de sanación", y en el entendido de que la "CPI tiene no solo una función punitiva, sino también de restauración. Esto refleja el creciente consenso internacional de que la participación y las reparaciones juegan un papel importante en el logro de la justicia para las víctimas" ${ }^{\prime 2}$. Sin embargo, la participación en los procesos penales no está exenta de dificultades, sobre todo cuando entra en conflicto con los derechos de los acusados ${ }^{28}$. Las Cámaras Extraordinarias en los tribunales de Camboya

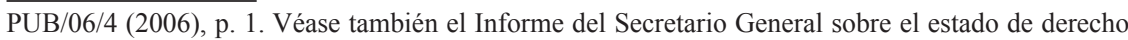
y la justicia de transición, supra nota 6, párr. 34; K. McCourt, Judicial Defenders: Their Role in Postgenocide Justice and Sustained Legal Development, 3 "The International Journal of Transitional Justice", 2009, pp. 272-273: 'long-term and sustainable solutions to impunity should aim mostly at building domestic capacity to try [international] crimes'.

${ }^{24}$ Doc. ONU. S/RES/1503 (2003), inter alia, 'Noting that the strengthening of national judicial systems is crucially important to the rule of law in general and to the implementation of the ICTY and ICTR Completion Strategies in particular'. Véase también la declaración del 23 de julio 2002 formulada por el Presidente del Consejo de Seguridad, Doc. ONU. S/PRST/2002/21.

${ }^{25}$ Véase, de manera general, J. E. Stromseth, Pursuing Accountability for Atrocities After Conflict: What Impact on Building the Rule of Law?, 38 “Geo. J. Int'1 L.” 251, 2006-2007, pp. 256 y 279: 'too little too late'.

${ }^{26}$ Corte Penal Internacional, Informe de la Corte sobre la estrategia en relación con las víctimas, doc. ICC-ASP/8/45, 10 de noviembre de 2009, párr. 6. La Oficina del Fiscal también ha preparado un documento de políticas sobre participación de las víctimas, abril de 2010, en línea: http://www.icc-cpi.int/NR/rdonlyres/BC21BFDF-88CD-426B-BAC3-D0981E4ABE02/281751/ PolicyPaperonVictimsParticipationApril2010.pdf

${ }^{27}$ Ibid., párrs. 2-3, '...positive engagement with victims can have a significant effect on how victims experience and perceive justice and, as such, contribute to their healing process'. 'ICC has not only a punitive but also a restorative function. It reflects growing international consensus that participation and reparations play an important role in achieving justice for victims'.

${ }^{28}$ See S. Zappalà, The Rights of Victims v. the Rights of the Accused, 8 "Journal of International Criminal Justice", 2010, p. 137. 
y el Tribunal Especial para el Líbano también permiten la participación de las víctimas en los procesos judiciales ${ }^{29}$. Esto confirma la tendencia a reconocer a las víctimas no sólo como testigos potenciales y fuentes de información, sino como actores activos del proceso penal a los que se otorgan derechos específicos ${ }^{30}$. En cuanto a la creación de capacidad nacional, como veremos más adelante, el principio fundacional de la CPI - la complementariedad- es probablemente el impacto más prometedor que la CPI pudiera tener en la empresa global de lucha contra la impunidad de los peores crímenes internacionales.

\section{El camino a seguir: una justicia pragmática como una responsabilidad compartida.}

\section{a. Sin vuelta atrás: un sistema de Justicia Penal Internacional basado en fundamentos incuestionables}

Es algo trillado decir que los tribunales ad hoc y la CPI se crearon sobre los cimientos de Nuremberg y, especialmente la CPI, que estaban destinados a proporcionar un hogar permanente a la noble idea de que "los crímenes contra el derecho internacional son cometidos por hombres, no por entidades abstractas, y sólo castigando a los individuos que cometen tales crímenes pueden fortalecerse las disposiciones del derecho internacional". ${ }^{31}$ Este principio es el de la responsabilidad penal individual, la noción de que detrás de las cortinas de la estatalidad hay en realidad personas cometiendo, ordenando, planificando, etc., crímenes internacionales. Actualmente, este principio se encuentra firmemente arraigado tanto en tratados como en el derecho internacional consuetudinario, como se apuntó anteriormente, y no puede ser ignorado, tanto en la ley como en la práctica. Los tribunales penales internacionales han tenido un papel indiscutible en la promoción y construcción del Estado de derecho a nivel internacional y en la construcción de un orden público normativo internacional.

Es innegable que los estatutos y los tribunales penales internacionales han

\footnotetext{
${ }^{29}$ Véanse, por ejemplo: Regla 23 del Reglamento Interno de la ECCC; Reglas 86-87 STL RPE; Exposición de motivos de la Presidenta del Tribunal, 10 de junio de 2009, párr. 14; para un comentario, véase J. de Hemptinne, Challenges Raised by Victims'Participation in the Proceedings of the Special Tribunal for Lebanon, 8 "Journal of International Criminal Justice", 2010, p. 165.

${ }^{30}$ Hay un número creciente de interpretaciones jurisprudenciales de los criterios necesarios para calificar como víctima en virtud del art. 68 (3) del Estatuto de la CPI, contemplados en el concepto de daño sufrido por la víctima y el vínculo con el presunto delito. Véase, por ejemplo, la situación en la República Democrática del Congo - Caso Lubanga, Sentencia de apelación del Fiscal y la Defensa contra la Decisión de la Sala de Asuntos Preliminares sobre la Participación de las Víctimas del 18 de enero de 2008, Caso No. ICC-01/04-01/06-1432, 11 de julio de 2008.

${ }^{31}$ Juicio a los Principales Criminales de Guerra ante el Tribunal Militar Internacional, Nuremberg, noviembre 14, 1945 a octubre 1, 1946, publicado en Nuremberg, Alemania, 1947, p. 223, "crimes against international law are committed by men, not by abstract entities, and only by punishing individuals who commit such crimes can the provisions of international law be enforced".
} 
aportado una mayor claridad a las definiciones de los crímenes internacionales y a los modos de participación de tales crímenes. La impresionante cantidad de jurisprudencia emanada de estos tribunales, y la vibrante literatura académica que lo acompaña, hicieron sin duda una inmensa contribución al marco jurídico internacional. Valga mencionar ahora como ejemplo, para sus fines, el impacto tremendo en la definición del delito de genocidio de los dos primeros juicios por genocidio, en Akayesu $^{32}$ y Kambanda ${ }^{33}$, que dieron una vitalidad y relevancia sin precedentes a la Convención de $1948^{34}$, en particular al declarar que el genocidio es "innegablemente considerado como parte del derecho internacional consuetudinario" 35 . La sentencia Akayesu también es innovadora en su afirmación sobre la violación sexual como constitutiva de crímenes internacionales ${ }^{36}$. Al igual que otros delitos de violencia sexual, ahora se considera como delito subyacente de todos los crímenes principales en los tribunales internacionales y también puede ser constitutivo de tortura o persecución ${ }^{37}$. El Estatuto de Roma codificó esta declaración del derecho internacional consuetudinario y enumera diversos actos de violencia sexual dentro de sus definiciones de crímenes de lesa humanidad y crímenes de guerra ${ }^{38}$.

Uno de los avances más significativos en el derecho penal internacional se ha producido con respecto a los crímenes de lesa humanidad. Estos delitos se han desarrollado más allá de su relación con conflictos armados y su definición se ha ido refinando progresivamente (con respecto al ataque como requisito, por ejemplo) y ampliado (una extensa lista de delitos sexuales y desaparición forzada, por ejemplo). Cubren una amplia gama de conductas cometidas tanto en tiempos de guerra como de paz, que no necesariamente se clasifican como genocidio o crímenes de guerra. A pesar de la ausencia actual de un tratado específico relativo a los crímenes de lesa humanidad, actualmente se les considera parte central del ordenamiento jurídico penal internacional. En cuanto a los crímenes de guerra, los tribunales ad hoc y el Estatuto de la CPI

\footnotetext{
${ }^{32}$ El Fiscal contra Akayesu, supra, nota 22.

${ }^{33}$ El Fiscal contra Kambanda, sentencia y condena, Caso No. ICTR-97-23-S, T. Ch., 4 de septiembre de 1998.

${ }^{34} 1948$ Convención de Nueva York para la Prevención y la Sanción del Delito de Genocidio, 78 UNTS 277; P. Akhavan, The Crime of Genocide in the ICTR Jurisprudence, 4 "Journal of International Criminal Justice,"(2005)989, en 990.

${ }^{35}$ El Fiscal contra Akayesu, supra, nota 22, p. 495, 'undeniably considered part of customary international law'.

${ }^{36}$ El Fiscal contra Akayesu, supra, nota 22, p. 495.

${ }^{37}$ Véase El Fiscal contra Semanza, Juicio y Sentencia, Caso No. ICTR-97-20-T, T.Ch. III, 15 de mayo de 2003; El Fiscal contra Gacumbitsi, Sentencia, Caso No. ICTR-01-64-T, T.Ch. III, 17 de junio de 2004, párr. 215; El Fiscal contra Nahimanay al., Juicio y Sentencia, Caso No. ICTR-99-52-T, T.Ch., 3 de diciembre de 2003. La prueba de igual gravedad ha ayudado a ampliar el alcance de los actos comprendidos en el delito de persecución: El Fiscal contra Karadzic, Decisión sobre seis mociones preliminares desafiando Jurisdicción, Caso No. IT-95-5/18-PT, T.Ch., 28 de abril de 2009, párr. 43.

${ }^{38}$ Estatuto de Roma, Arts. 7 (1) (g), 8 (b) (xxii) y 8 (e) (vi). Los Elementos de los Crímenes de la Corte Penal Internacional, ICC-ASP OR, ICC-ASP/1/3, 2002, 108, también confirman que pueden ser constitutivos de genocidio, art. 6 (b), nota 3.
} 
han hecho numerosas contribuciones importantes, siendo la más significativa y conocida la extensión del régimen jurídico aplicable a crímenes de guerra en conflictos armados internos ${ }^{39}$. Este desarrollo ha sido codificado de manera general por el Estatuto de la CPI, que establece la lista hasta ahora más detallada de delitos subyacentes constitutivos de crímenes de guerra cometidos en conflictos armados internos ${ }^{40}$.

Además de las definiciones de delitos, las instituciones penales internacionales han definido modos de participación individual, tratando de encontrar una manera de tratar la responsabilidad penal individual en un contexto en el que haya una pluralidad de autores, algunos de los cuales pudieran no haber cometido físicamente el crimen ${ }^{41}$. Las doctrinas de la responsabilidad del superior y de la empresa criminal conjunta fueron desarrolladas para hacer frente a lo que se ha denominado 'criminalidad sistemática' ${ }^{42}$. A pesar de que han sido objeto de críticas $^{43}$, las doctrinas han sido la base para un gran número de condenas ante todos los tribunales penales internacionales ${ }^{44} \mathrm{y}$ han contribuido, junto con la literatura vibrante que han estimulado, a la construcción de un mejor entendimiento de cómo el derecho penal puede capturar la criminalidad masiva y colectiva. Por último, es notable que la construcción de la justicia penal internacional también haya contribuido a debilitar la base legal para las amnistías por violaciones graves a los derechos humanos, haya abierto una brecha en el antiguo régimen legal en materia de inmunidades y haya limitado en gran medida la aplicación de plazos de prescripción; avances oportunos todos ellos si aplicados dentro del marco de la ley, lo que implica la preservación de la soberanía estatal.

La responsabilidad penal individual por genocidio, crímenes de lesa humanidad y crímenes de guerra llegó para quedarse. No habrá marcha atrás hacia un vacío legal que permita a los presuntos autores de genocidio, crímenes de lesa humanidad y crímenes de guerra retirarse a unas vacaciones tranquilas en algún lugar en la playa -si no en todos los casos en la práctica, al menos en términos de la retórica de los estados y, sobre todo, en el derecho

\footnotetext{
${ }^{39}$ Secretario General, 'Informe del Secretario General de conformidad con el párrafo 5 de la Resolución 955 del Consejo de Seguridad “, doc. S/1995/134 13 de febrero de 1995, párr. 12; Véase, Tadic, supra, nota 22, párr. 134; El Fiscal contra Delalic, Sentencia, Caso N ${ }^{\circ}$ IT-96-21, T. Ch., 16 de noviembre de 1998, párr. 308; L. Moir, Grave Breaches and Internal Armed Conflicts, 7 "Journal of International Criminal Justice”, 2009, pp. 763 y 764; D. Plattner, The Penal Repression of Violations of International Humanitarian Law Applicable in Non-international Armed Conflicts, 30:278 "International Review of the Red Cross", 1990, pp. 409 y 414.

${ }^{40}$ Art. 8 (2) (c) y (e) del Estatuto de la CPI.

${ }^{41}$ H. G. Van der Wilt, The Continuous Quest for Proper Modes of Criminal Responsibility, 7:2 "Journal of International Criminal Justice", 2009, pp. 307-8.

${ }^{42}$ Ibid., 'system criminality'.

${ }^{43}$ Véase, entre otros, J. D. Ohlin, Three Conceptual Problems with the Doctrine of Joint Criminal Enterprise, 5:1 "Journal of International Criminal Justice", 2005, pp. 69-90.

${ }^{44}$ G. Boas, J. L. Bischoff and N. L. Reid, Forms of Responsibility in International Criminal Law, Vol. 1 Cambridge University Press, 2007, p. 9.
} 
internacional. Para corregir las debilidades existentes del sistema de justicia penal internacional actual es necesario trabajar desde su interior en lugar de presionar sin sentido para su ruptura.

Dicho esto, el camino hacia el futuro no será necesariamente el mismo del pasado. Con los tribunales ad hoc la comunidad internacional decidió favorecer una forma distante y descarnada de justicia, poniendo el énfasis en tribunales internacionales. En el corazón del sistema puesto en marcha por la CPI, para garantizar la rendición de cuentas por los crímenes principales se encuentra más bien el principio de complementariedad. Los Estados tienen la responsabilidad primordial de enjuiciar a los responsables de crímenes internacionales. La CPI ejercerá su jurisdicción sólo si el Estado competente es inoperante, "incapaz" o "sin voluntad" a hacerlo ${ }^{45}$. Las legislaciones nacionales están llamadas, en consecuencia, a desempeñar un papel cada vez más importante en el sistema global puesto en marcha para luchar contra la impunidad. Al actuar a nivel local a fin de garantizar la justicia por los crímenes internacionales, los Estados pueden de hecho realizar una contribución significativa para el "desarrollo sustentable" de la justicia penal internacional ${ }^{46}$. Los mecanismos de justicia penal internacional no desaparecerán; más bien el sistema de justicia penal internacional se apoyará como nunca antes en los Estados para implementar el derecho penal internacional.

\section{b. Una transición hacia los Estados}

El Estatuto de Roma, establece en su preámbulo ${ }^{47}$, y por inferencia del principio de complementariedad, la obligación de los Estados partes de enjuiciar los crímenes internacionales previstos en el mismo. La Cámara de Apelaciones de la CPI ha reconocido que los Estados "tienen el deber de ejercer su jurisdicción penal sobre crímenes internacionales"48. Sin embargo, no existe ninguna obligación explícita en el Estatuto de Roma relativa a los Estados partes para establecer su jurisdicción sobre los delitos y, ciertamente, ninguna obligación de fundamentarla sobre la base de la universalidad ${ }^{49}$. Con independencia de la ausencia de una clara obligación en este sentido en el Estatuto, muchos Estados han aprovechado la oportunidad surgida de la necesidad de modificar

\footnotetext{
${ }^{45}$ Estatuto de Roma, Artículo 17, Artículo 1 y Párrafo 6 del Preámbulo.

${ }^{46}$ Véase Fannie Lafontaine, Prosecuting Genocide, Crimes against Humanity and War Crimes in Canadian Courts, Carswell, 2012.

${ }^{47}$ Estatuto de Roma, preámbulo, párrs. 4 y 6.

${ }^{48}$ El Fiscal contra Germain Katanga y MathieuNgudjoloChui, ICC-01/04-01/07, Sentencia sobre la Apelación del Sr. Germain Katanga contra la decisión oral de la Sala de Primera Instancia II del 12 de junio de 2009 sobre la admisibilidad de la causa (25 de septiembre 2009), párrafo 85 (CPI, Sala de Apelaciones). ("have a duty to exercise their criminal jurisdiction over international crimes").

${ }^{49}$ Véase, por ejemplo, Payam Akhavan, Whither National Courts? The Rome Statute's Missing Half, 8 “Journal of International Criminal Justice”, 2010, pp. 1245-1248.
} 
su legislación interna para implementar sus obligaciones referentes al Estatuto de Roma, a fin de conceder a sus tribunales nacionales competencia para juzgar estos crímenes, inclusive sobre la base de la universalidad. El "tren de la CPI" está creando un impulso irrevocable hacia la penalización de los agravios de la CPI en las legislaciones nacionales y hacia el otorgamiento de jurisdicción a tribunales nacionales para juzgar estos crímenes. Muchos observadores afirman que el impacto del principio de complementariedad en los sistemas jurídicos nacionales, en particular si se promueve "de manera proactiva" por los órganos de los tribunales, es la contribución más prometedora de la CPI a la lucha contra la impunidad y en pro de la paz y la seguridad duraderas ${ }^{50}$.

Este renovado (o nuevo) énfasis en los sistemas nacionales tiene al menos dos consecuencias, además de la que acabamos de mencionar, a saber, la necesidad de modificar las leyes nacionales para cumplir con las obligaciones y responsabilidades de derecho penal internacional. La primera es que los Estados donde ocurrieron los crímenes o aquellos cuya nacionalidad detenta el presunto autor tienen una responsabilidad especial para garantizar que los crímenes no queden impunes. Dos observaciones pueden hacerse con respecto a esta habitual afirmación. Primero, los Estados territoriales o nacionales no cuentan precisamente con un linaje inmaculado en este sentido. De hecho, la necesidad de internacionalizar las iniciativas de rendición de cuentas para hacer frente a violaciones de derechos humanos se debe a menudo a la falta de capacidad institucional o voluntad política a nivel local. En segundo lugar, tener la responsabilidad primordial de investigar y procesar crímenes internacionales es tal vez un privilegio respetuoso de la soberanía del Estado, pero también es un deber muy oneroso. Es fácil darse cuenta de las dificultades intrínsecas que los Estados que salen de conflictos pueden enfrentar para mantenerse a la altura de este desafío, sobre todo en lo que respecta a garantizar un juicio justo a los sospechosos, en un entorno político no siempre favorable a tan nobles objetivos ${ }^{51}$. También se están pasando ciertas dificultades en el intento de hacer rendir cuentas a los simpatizantes del presidente en funciones que presuntamente han cometido violaciones al derecho internacional ${ }^{52}$. Del mismo modo, desde hace décadas numerosos estados y el TPIR han tenido grandes dificultades con la extradición o traslado de sospechosos a Ruanda, a pesar de la clara voluntad política que hay para hacerse cargo de los casos,

${ }^{50}$ Véase, por ejemplo, W.W. Burke-White, Proactive Complementarity: The International Criminal Court and National Courts in the Rome System of Justice, 49, "Harv. Int'1 L. J.", 2008, p. 53; M. S. Ellis, International Justice and the Rule of Law: Strengthening the ICC through Domestic Prosecutions, 2009, 1, "Hague Journal on the Rule of Law", p. 79.

${ }^{51}$ ver CPI, Situacion en Costa de Marfil, Decision Pursuant to Article 15 of the Rome Statute in the Authorization of an Investigation into the Situation in the Republic of Côte d'Ivoire», ICC-02/11, 3 de octubre 2011, nota de pie 14, http://www.icc-cpi.int/iccdocs/doc/doc1240553.pdf

${ }^{52}$ Supporting National Prosecutions in Côte d'Ivoire, International Center for Transitional Justice, 6 de junio de 2013, en linea :http://ictj.org/news/supporting-national-prosecutions-cote-divoire

Araucaria. Revista Iberoamericana de Filosofía, Política y Humanidades, año 16, n 32. Segundo semestre de 2014. Pp. 339-358. ISSN 1575-6823 e-ISSN 2340-2199 doi: 10.12795/araucaria.2014.i32.17 
esencialmente debido a las preocupaciones por la seguridad de los sospechosos o, más a menudo, por temor a que pudieran no tener un juicio justo. Este debate continuo ha llevado a una decisión importante realizada por una Sala del Tribunal Europeo de Derechos Humanos (ECHR) el 27 de octubre de 2011, que desestimó la demanda de un sospechoso de genocidio ruandés que enfrentaba la extradición a Ruanda por Suecia, ya que, de acuerdo con la Corte, "no corría el riesgo de una flagrante denegación de justicia"53. La Sala de Apelaciones del TPIR, en diciembre de 2011, confirmó la transferencia de Jean Bosco Uwinkindi a los tribunales ruandeses, un primer ejemplo de transferencia del TPIR ${ }^{54}$, y subsecuentemente algunos Estados han permitido también dichas transferencias, no sin preocupación expresa de los acusados de que un juicio justo sería ilusorio en el contexto político actual ${ }^{55}$. Como último ejemplo, basta con mencionar la lucha de Libia para convencer a la CPI y a la opinión mundial de que puede ofrecer y que ofrecerá un juicio justo a Saif AlIslam Gadaffi ${ }^{56}$. La responsabilidad de garantizar la rendición de cuentas por crímenes internacionales trae como consecuencia desafíos altamente delicados para los Estados involucrados.

Una segunda consecuencia de esta transición hacia los Estados en la lucha global contra la impunidad por crímenes internacionales es que donde los Estados territoriales o nacionales no hagan por investigar o no puedan investigar y procesar, no solamente la CPI puede actuar como último baluarte contra la impunidad, sino también Estados terceros, especialmente a través del principio de jurisdicción universal. La jurisdicción universal es el ejercicio de la jurisdicción de un Estado por delitos que, en el momento de su comisión, no tuvieran ningún vínculo territorial o nacional con el Estado en cuestión. Es evidente que no puede esperarse que la CPI sea capaz de garantizar justicia para todos los autores de crímenes internacionales, pero como Cesare Beccaria señaló ya en 1764, "la convicción de no encontrar en ningún lugar un palmo

\footnotetext{
${ }^{53}$ Caso Ahorugeze contra Suecia, TEDH (2011), Solicitud no. 37075/09. 'he would not risk a flagrant denial of justice'.

${ }^{54}$ Decisión sobre la Apelación de Uwinkindi contra la Remisión de su caso a Ruanda y mociones relacionadas, Uwinkindi, (ICTR-01-75-AR11bis), Sala de Apelaciones, 16 de diciembre de 2011.

${ }^{55}$ Véase como ejemplo la expulsion de Léon Mugesera de Canadá: Motifs d'une décision en application de l'alinéa 115(2)b) de la Loi sur l'immigration et la protection des réfugiés (LIPR), numéro de dossier HQ7-65767, en archivo con autor, en 53 y la discusión sobre las garantías al debido proceso de manera general en 57-63. Véase discussion en F. Lafontaine, Mugesera: Canada's First Faltering Steps in the Debate Over Transferring Genocide Suspects to Rwanda, en línea: http:// rjcurrie.typepad.com/international-and-transna/2012/01/mugesera-canadas-first-faltering-steps-inthe-debate-over-transferring-genocide-suspects-to-rwanda.html

${ }^{56}$ Véase, por ejemplo, Libyan Government's consolidated reply to the responses of the Prosecution, $O P C D$, and $O P C V$ to its further submissions on issues related to the admissibility of the case against Saif Al-Islam Gaddafi, No.: ICC-01/11-01/11, 4 de marzo de 2013, en línea: http://www. icc-cpi.int/iccdocs/doc/doc1562659.pdf. La cámara de apelaciones ha recientemente acabado con el argumento:Judgment on the appeal of Libya against the decision of Pre-Trial Chamber I of 31 May 2013 entitled "Decision on the admissibility of the case against Saif Al-Islam Gaddafi», ICC-01/1101/11-547-Red(21 de mayo de 2014).
} 
de tierra donde crímenes reales sean indultados, podría ser la forma más eficaz

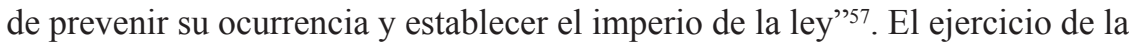
jurisdicción universal puede, en mi opinión, contribuir a cerrar la "brecha de impunidad", asegurando que los responsables de crímenes internacionales no evadan la justicia. Empero, esta extraordinaria competencia judicial no deja de comportar sus propios desafíos, ya se trate, para la Fiscalía como para la Defensa, de reunir pruebas, obtener la cooperación del Estado territorial, aplicar el derecho internacional en un contexto extranjero desconocido, financiar investigaciones y juicios, gestionar las tensiones políticas que pudieran resultar de manera inevitable, etc. Sin embargo, la responsabilidad colectiva para combatir la impunidad depende en gran medida del compromiso formal de todas las naciones. Este compromiso debe estar dirigido a garantizar el buen funcionamiento de las instituciones internacionales que se han establecido para tal fin, como la CPI, pero debe también incluir la voluntad y la capacidad de utilizar las instituciones nacionales para la realización de un mismo objetivo fundamental ${ }^{58}$.

\section{Conclusión}

Mucho se esperaba de los tribunales creados por el Consejo de Seguridad de las Naciones Unidas en medio de los acontecimientos terribles de Ruanda y de la ex Yugoslavia: restauración y mantenimiento de la paz y la seguridad, disuasión, reconciliación, educación, búsqueda de la verdad, retribución, denuncia, reparación, etc. La CPI fue creada en 1998 en este entorno de grandes esperanzas y grandes expectativas, que ninguna institución del derecho penal -ya sea nacional o internacional- podría nunca satisfacer. Después de casi veinte años desde el renacimiento de la justicia penal internacional surge un acuerdo común: la justicia penal es tan sólo una medida que puede utilizarse en situaciones actuales y post-conflicto y no debemos esperar de ella más de lo que puede ofrecer.

La raison d'être de la justicia penal internacional -la idea de la responsabilidad penal individual por los crímenes internacionales más gravesllegó para quedarse. No habrá marcha atrás hacía un vacío legal donde ninguna ley o ninguna institución pueda aplicar este principio. La CPI no es tan sólo una institución internacional: ha creado un sistema global para luchar contra la

\footnotetext{
57 A. Cassese, On the Current Trends towards Criminal Prosecution and Punishment of Breaches of International Humanitarian Law, 9 "EJIL", 1998, pp. 2-17, citando a Beccaria, Dei delitti e delle pene, translated in J. Farrar, Crimes \& Punishment (1880), pp. 193-194 ('the conviction of finding nowhere a span of earth where real crimes were pardoned might be the most efficacious way of preventing their occurrence' and the rule of law').

58 F. Lafontaine, Universal Jurisdiction: The Realistic Utopia, 10 "Journal of International Criminal Justice”, 2012, pp. 1277-1302.
} 
impunidad de aquellos responsables de la comisión de genocidio, crímenes de lesa humanidad y crímenes de guerra, un sistema que se basa principalmente en los Estados. El futuro del sistema global de rendición de cuentas por crímenes internacionales se basa principalmente en los Estados. El fortalecimiento de las leyes nacionales y las instituciones judiciales es el desafío prioritario de las próximas décadas. La voluntad política de permitir que la justicia siga su rumbo, su principal amenaza. Los recientes éxitos o los intentos de los tribunales nacionales de los Estados como Guatemala, Argentina y Haití, y el uso de la jurisdicción universal no sólo en los Estados occidentales, como Canadá, España, Bélgica y análogos, sino también en Senegal, Sudáfrica y Argentina, tal vez apunta a lo que podría constituir el impacto más profundo del sistema creado por la CPI: la justicia debe ser un asunto de todos, si el objetivo es que no se dirija únicamente contra unos cuantos. 


\section{Referencias bibliográficas:}

A. Cassese, On the Current Trends towards Criminal Prosecution and Punishment of Breaches of International Humanitarian Law, 9, "EJIL", 1998.

A. Seibert - Fohr, Reconstruction through Accountability, 9 "Max Planck Yearbook of UnitedNationsLaw", 2005.

A-M De Brouwer, Supranational criminal prosecution of sexual violence: the ICC and thepractice of the ICTY and the ICTR, Intersentia, 2005, págs. 394 y ss.

C. Reiger, 'Fulfilling the Justice Promise: Guiding Principles for Resolving the Ongoing Responsibilities of International Tribunals', 8 de octubre de 2009, en 2, http://www.ictj.org/static/Prosecutions/Arria_Presentation091008.pdf

Cryer et al., An Introductionto International Criminal Law and Procedure, Oxford, 2007, en págs. 31-33 y 58-61.

F. Lafontaine, Prosecuting Genocide, Crimes against Humanity and War Crimes in Canadian Courts, Carswell, 2012.

F. Lafontaine, Universal Jurisdiction: The Realistic Utopia, 10 "Journal of International Criminal Justice", 2012.

G. Boas, J. L. Bischoff and N. L. Reid, Forms of Responsibility in International Criminal Law, Vol. 1 Cambridge University Press, 2007.

H. G. Van der Wilt, The Continuous Quest for Proper Modes of Criminal Responsibility, 7:2 “Journal of International Criminal Justice”, 2009.

J. Alvarez, Rush to Closure: Lessons from the Tadić Judgment, 96 "Mich. L. Rev.", 1998.

J. D. Ohlin, Three Conceptual Problems with the Doctrine of Joint Criminal Enterprise, 5:1 "Journal of International Criminal Justice", 2005.

J. de Hemptinne, Challenges Raised by Victims'Participation in the Proceedings of the Special Tribunal for Lebanon, 8 "Journal of International Criminal Justice", 2010.

J. E. Stromseth, Pursuing Accountability for Atrocities After Conflict: What Impact on Building the Rule of Law?, 38 “Geo. J. Int'1 L.”, 2006-2007. págs 251- 256.

J. E. Stromseth, Pursuing Accountability for Atrocities After Conflict: What Impact on Building the Rule of Law?, 38 “Geo. J. Int'1 L.”, 2006-2007. págs. 256-279.

J. Farrar, Crimes \& Punishment, 1880. págs. 193-194.

L. Otis and E. H. Reiter, Front-Line Justice, 46 "Virginia Journal of International Law", 2006.

M. Husejnovic and E. Mackic, Victims Miss Out on Right to Compensation, Balkan Investigative Reporting Network Informe de Justicia, 4 de marzo de 2009. 
M. Minow, Between Vengeance and Forgiveness, Beacon Press, 1999.

M. Osiel, Mass Atrocity, Collective Memory and the Law, New Brunswick, New Jersey, Transaction Publishers, 1997

M. S. Ellis, International Justice and the Rule of Law: Strengthening the ICC through Domestic Prosecutions, 2009. "Hague Journal on the Rule of Law".

McCourt, Judicial Defenders: Their Role in Postgenocide Justice and Sustained Legal Development, 3 "The International Journal of Transitional Justice", 2009, págs. 272-273.

N. Roth-Arriaza, 'Introduction', in N. Roth-Arriaza (ed.), Impunity and Human Rights in International Law and Practice, New York, Oxford University Press, 1995.

P.W. Kahn, Speaking Law to Power: Popular Sovereignty, Human Rights, and the New International Order, 1, "Chicago Journal of International Law", 2000. págs. $1-18$

Payam Akhavan, Whither National Courts? The Rome Statute's Missing Half, 8 "Journal of International Criminal Justice", 2010.

Rob Crilly, Saving Darfur: Everyone's Favourite African War, Reportage Press, 2010, pág. 39-40.

S. Malstrom, Restitution of Property and Compensation to Victims, en Mayo y al. (eds.), Essays on ICTY Procedure and Evidence in Honour of Gabrielle Kirk McDonald, Kluwer Law International, 2001.

S. Mohamed, A Neglected Option: The Contributions of State Responsibility for Genocide to Transitional Justice, 80"University of Colorado Law Review", 2009.

S. Zappalà, The Rights of Victims v. the Rights of the Accused, 8 "Journal of International Criminal Justice", 2010.

W. A. Schabas, The UN international criminal tribunals: the former Yugoslavia, Rwanda and Sierra Leone, Cambridge, Cambridge University Press, 2007. págs. 149 y ss.

W.W. Burke-White, Proactive Complementarity: The International Criminal Court and National Courts in the Rome System of Justice, 2008. 